\title{
DC plasma-polymerized hexamethyldisilazane coatings of an equiatomic TiNi shape memory alloy
}

\author{
Mu-Rong Yang, S.K. Wu* \\ Institute of Materials Science and Engineering, National Taiwan University, Taipei 106, Taiwan
}

Received 5 January 2000; accepted in revised form 22 February 2000

\begin{abstract}
The TiNi corrosion resistance of $\mathrm{Ti}_{50} \mathrm{Ni}_{50}$ shape memory alloy can be substantially improved by DC plasma-polymerized hexamethyldisilazane (PHMDSN) coatings. The initial PHMDSN deposition rate increases with increasing DC voltage. The deposition rate decreases gradually with time until the glow discharge is extinguished. The higher DC voltage used in plasma polymerization will develop a film with a more inorganic nature from the IR spectrum analysis and water contact angle measurements. The PHMDSN coatings for DC voltage $\geq 1000 \mathrm{~V}$ are protection against the corrosion in Ringer's solution and can be deformed up to a $2 \%$ strain. The corrosion current density of the TiNi alloy can be lowered by as many as four orders of magnitude. The pitting potential and re-passivation potential can also be enhanced to nobler potential after PHMDSN coatings. The widely scattered pitting potential of the as-homogenized TiNi can also be improved by the PHMDSN coatings. (C) 2000 Elsevier Science S.A. All rights reserved.
\end{abstract}

Keywords: DC plasma-polymerized hexamethyldisilazane (PHMDSN) coatings; TiNi shape memory alloy; Corrosion resistance improvement

\section{Introduction}

Since the US Naval Ordnance Laboratory discovered the shape-memory phenomena in an equiatomic nickel titanium alloy [1], shape memory materials have drawn a lot of attention for decades, as functional materials in a variety of industrial and medical applications.

The excellent shape memory effect (SME) and superelastic (psuedoelastic) behavior (PE) of equiatomic TiNi alloy allow it to exhibit good biofunctionability in bio-medical applications such as the minimal access surgery (i.e. laparoscopic surgery) [2], intracoronary stent [3], the replacement of ligaments [4], the shape memory microvalve to control drug delivery precisely [5], bone stamp and the osteosynthesis devices [6], etc.

\footnotetext{
* Corresponding author. Tel.: +886-2-2363-7846; fax: +886-22363-4562.

E-mail address: skw@ccms.ntu.edu.tw (S.K.Wu)
}

Hence the TiNi alloy can be used as a long-term implant and its biocompatibility should be established.

The biocompatibility of metal implants is generally evaluated by the reaction (or damage) between the metal and the surrounding tissue. The intensity of damage caused by metallosis is proportional to the quantity of (toxic) metallic ions produced by corrosion. In the $\mathrm{TiNi}$ alloy, the $\mathrm{Ti}$ is not among the essential trace elements [7]. However, Ni alloy proves to exhibit high carcinogenic and toxic potencies in vivo regardless of the fact that $\mathrm{Ni}$ is an essential element to the human body [8]. Hence, the passivity current density of the implanted metal in a potentiostatic condition can be taken as an index of the ion release of the metal and this current density is sufficient to be an indicator of their biocompatibility [9].

Although the corrosive behavior of TiNi alloy has been extensively investigated, some contradicting results of in vivo and in vitro measurements of anodic 
polarization render this alloy less safe for medical application. The corrosion resistance of TiNi alloy has been found to be superior to the 316L stainless steel and corresponds to that of titanium [10]. The TiNi alloy shows no cytotoxic, allergic or genotoxic activity, similar to the clinical reference control materials AISI 316LVM stainless steel [11]. However, some researchers found conflicting results $[12,13]$. The widely scattered corrosion behavior of TiNi alloy is also observed in other reports on electrodynamic polarization [14-17].

Since the corrosion resistance depends on the surface properties of the alloy, many surface modifications have been considered. Efforts to improve this resistance by covering the TiNi surface with bioceramic (TiN, TiCN, $\mathrm{Al}_{2} \mathrm{O}_{3}, \mathrm{SiC}, \mathrm{BN}$ and $\mathrm{Si}_{3} \mathrm{~N}_{4}$ ) thin films fail, due to the cracking of these coatings because of large deformations induced by the SME [17,18]. The recoverable strain of the SME of TiNi alloy is more than 5\% [1], which is much larger than the elastic strain of these bioceramic coatings. The oxide films, obtained by heating the TiNi alloy at $900^{\circ} \mathrm{C}$ for $10 \mathrm{~min}$, produce positive results on corrosion resistance as well as on biocompatibility and cracks do not appear. However, the heating of whole bulk can modify the transformation temperatures of TiNi alloy and its shape memory. The $\mathrm{N}^{+}$ implantation of TiNi can not only enhance the pitting and crevice corrosion resistance substantially, but also the wear resistance $[19,20]$. However, for a complex geometrical shape such as staples, it is very difficult to treat them by this technique. In addition, the laser treatment of TiNi alloy can double the autopassivating range, yielding a greater resistance to pitting corrosion. Nevertheless, this technique is very expensive and not very appropriate for implants of complex geometry [15]. Although the electropolished and nitric passivated treatments on the TiNi surface have many advantages over other methods and are very promising in the commercial applications, the improvement produced by the treatment is still limited. The treatment can lower the passivation current density by only one order of magnitude [21].

Plasma polymerization tetrafluoroethylene (PPTFE) coating with $0.4 \mu \mathrm{m}$ thickness deposited under $20 \mathrm{~W}$ at $13.56 \mathrm{MHz}$ for $20 \mathrm{~min}$ (at $40 \mathrm{mTorr}$ with $10 \mathrm{sccm}$ flow rate of $\mathrm{C}_{2} \mathrm{~F}_{4}$ monomer) can enhance the localized corrosion resistance because of the hydrophobicity of the PPTFE film avoids the massive attack of aggressive species in the solution [22]. However, the PPTFE film can lower the corrosion current density of only one order of magnitude and cannot reduce passive current density [22]. In contrast to the fluorine-containing monomer, the organosilicon will be more environmentally friendly and less corrosive to equipment. Oganosilicon monomers, in general, are sufficiently volatile, non-toxic and non-flammable, and relatively cheap (commercially available). Previous studies indicated that the plasma-polymerized methylsilcone film can not only enhance the blood clotting time [23] and anticalcific behavior [24], but can also provide an excellent passive film against corrosion [25]. Since the TiNi alloy is electrically conductive and the process of DC glow discharge provides a wide range of optimal operating condition, high deposition rate, good reproductivity and adhesion [25,26], the silicon-containing film deposited by DC glow discharge seems to be a viable method for an anticorrosive coating on the TiNi alloy. However, so far, there is no report on the study of the improvement of TiNi corrosion by DC plasma polymerized organosilicon coatings. In our research, the DC plasma polymerized hexamethyldisilazane (PHMDSN) coatings are employed to improve the corrosion of TiNi alloy. The relationship between the applied DC voltage and the chemical structure of PHMDSN coatings will also be discussed.

\section{Experimental procedures}

\subsection{Substrate preparation}

The $\mathrm{Ti}_{50} \mathrm{Ni}_{50}$ alloy was prepared from titanium (99.8 wt.\%) and nickel (99.98 wt.\%) using a vacuum/argon tungsten arc furnace. The casting ingot was hot-rolled into a 1-mm-thick sheet at $850^{\circ} \mathrm{C}$, and subsequently annealed at $850^{\circ} \mathrm{C}$ for $30 \mathrm{~min}$. The rolled sheet was cut into $10 \times 10 \times 1(\mathrm{~mm})$ specimens by a low-speed diamond saw. The surface was ground on $\mathrm{SiC}$ paper to remove oxide scale and then polished through a standard metallographic procedure to a final level of 0.3 $\mu \mathrm{m}$ alumina. Subsequently, all of the polished substrates were cleaned ultrasonically in cleaning reagents (Extran, MERCK Taiwan Ltd.), acetone and ethanol for $10 \mathrm{~min}$ to remove grease or organic contamination on the surface and then rinsed with de-ionized water, and finally air-dried. These specimens were stored in a dried box before use.

\subsection{Plasma polymerized HMDSN on TiNi alloy}

The DC plasma equipment, as schematically shown in Fig. 1, consists of a tubular type reactor made of Pyrex glass, which is vertically installed with anode atop (earth potential). The substrate $\left(\mathrm{Ti}_{50} \mathrm{Ni}_{50}\right.$ plate) is placed in the DC plasma equipment and connected to the cathode of high potential. The film formed on the cathode has a highly cross-linked density and the deposition rate on the anode is at least one order of magnitude less than that on the cathode [25]. The limiting current resistance (approx. $73.2 \mathrm{k} \Omega$ ) is needed to prevent the initial arc discharge and maintain the abnormal glow discharge. The substrate is cleaned in 


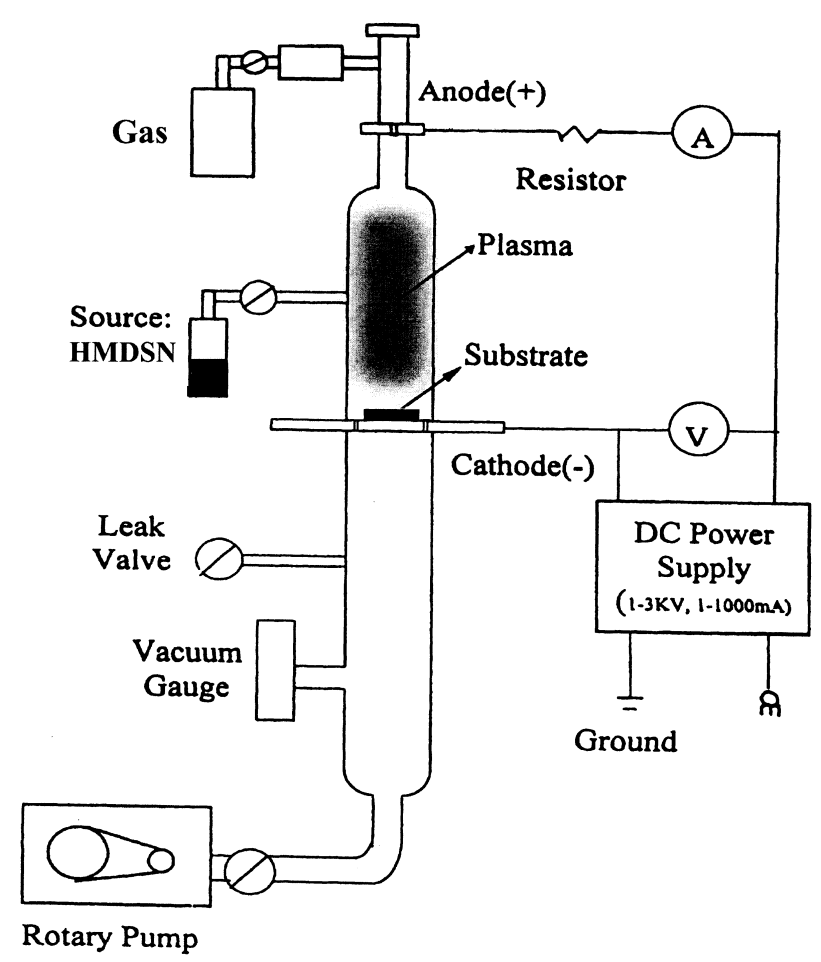

Fig. 1. Schematic diagram of the DC plasma apparatus.

situ prior to deposition by exposing the surface to argon (99.9\%) plasma for $3 \mathrm{~min}$ at $1000 \mathrm{~V}$. The argon pressure of 200 mTorr is maintained by a flow rate of $15 \mathrm{sccm}$. Hexamethyldisilazane monomer (HMDSN, Fluka Chemical Co. Inc.) is degassed by a freezepump-thaw cycle before use. After the system is evacuated to a base pressure of 10 mtorr or below, the monomer is introduced into the chamber and adjusted to a stable working pressure of $250 \mathrm{mTorr}$ by the continuous monomer vapor flow. The HMDSN monomer has sufficient high vapor pressure at room temperature and, therefore, does not require any external warming.

For a TiNi wire substrate (Kantoc Co. Japan, $\phi=0.25$ $\mathrm{mm}$ ), the anode is modified into a metallic cylinder and the TiNi wire substrate (cathode) is positioned coaxially and centrally within the anode.

\subsection{Characterization of the deposited films}

Film thickness is determined by the $\alpha$-step method. The measured thickness value is the average of five readings. Static contact angle is measured by ERMA Goniometer (Model G1, Erma Optical Works Co. Ltd., Japan) at room temperature $\left(26^{\circ} \mathrm{C}\right)$ and five readings are averaged. Fourier transformation infrared (FTIR) spectra are obtained using a FTIR spectrophotometer, Model A202 Spectrometer, to realize the functional groups formed after the glow discharge deposition. The spectra are obtained using a resolution of $4 \mathrm{~cm}^{-1}$ and are averaged over 40 scans.
Potentiodynamic polarization of the specimens is performed on AutoLab PGSTAT30 potentiostat in $27^{\circ} \mathrm{C}$ Ringer's solution (Sintong Chem. Ind. Co. Ltd., Taiwan). The composition of Ringer's solution is listed in Table 1 . The working electrode is a TiNi specimen and the potential is imposed on the working electrode vs. the reference electrode $(\mathrm{Ag} / \mathrm{AgCl}$ electrode). The applied voltage as well as the current flowing between the specimen and the platinum counter electrode is recorded automatically by data acquisition system. The voltage scanning rate is $300 \mathrm{mV} /$ min toward the anodic direction until the breakdown potential is reached.

The adhesion and coherence of the PHMDSN coatings on the TiNi specimen is evaluated by the bending test of the TiNi wire. The PHMDSN-coated TiNi wire is immersed in Ringer's solution and sealed in the transparent PU tube with the metallic electrode inside. The resistance between the TiNi wire and the metallic electrode in Ringer's solution is measured continuously by Keithely ${ }^{\circledR} 2000$ Multimeter. The bending performance and the electric resistance are recorded concurrently by video camera. If the film is ruptured by the bending, the electric resistance will be abruptly reduced. The radius of the curvature of the TiNi wire just before the PHMDSN film's rupture serves as the index to evaluate the adhesion and coherence of the PHMDSN film on the TiNi specimen.

\section{Results and discussion}

\subsection{Deposition rate}

The plasma polymerized HMDSN (PHMDSN) yields a yellowish film on TiNi substrate. Fig. 2 shows the film thickness vs. the deposition time under different voltages $(800 \mathrm{~V}, 1000 \mathrm{~V}, 1200 \mathrm{~V}$ and $1400 \mathrm{~V})$ at fixed monomer pressure of 250 mtorr. In the early stage, the film thickness seems to be proportional to the deposition time. It implies that a steady-state deposition is achieved within $100 \mathrm{~s}$. The deposition rate, approximately $6.7 \mathrm{~nm} / \mathrm{s}$ for $1400 \mathrm{~V}$, is faster by one order of magnitude than that of the RF plasma polymerization process [27]. The negative glow in the DC plasma contains a higher concentration of ions, electrons and other active species than the positive column [28]. The brightness in the negative glow zone, discernible with the naked eye, obviously increases with increasing the

Table 1

The composition of the Ringer's solution

\begin{tabular}{|c|c|}
\hline Constituent & $\mathrm{g} / 1$ \\
\hline $\mathrm{NaCl}$ & 8.6 \\
\hline $\mathrm{KCl}$ & 0.3 \\
\hline $\mathrm{CaCl}_{2} \cdot 2 \mathrm{H}_{2} \mathrm{O}$ & 0.33 \\
\hline $\mathrm{H}_{2} \mathrm{O}$ & Balance \\
\hline
\end{tabular}




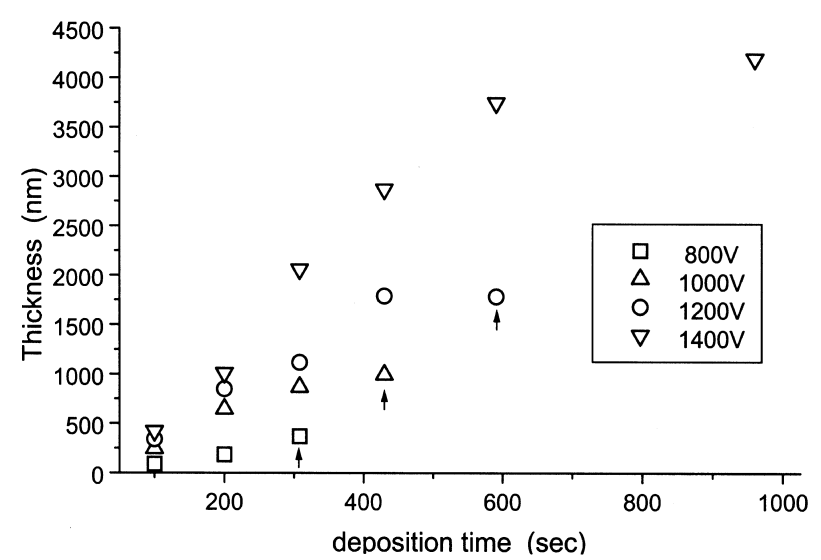

Fig. 2. Variation of the film thickness with deposition time at 250 mtorr HMDSN under different applied DC voltage.

applied DC voltage. Hence, the increase in the applied voltage in the DC glow discharge, especially in the negative glow region, will lead to a greater fragmentation of monomer and provide more active species to deposit. At the same time, the larger potential drop in the zones adjacent to the cathode, in which the major fraction of the potential drop between electrodes is concentrated [28], will also accelerate the ions to bombard the cathode more intensively. The initial deposition rate increases with increasing the applied voltage. As the deposition time elapses, the film thickness tends to level off. The decreasing deposition rate, with time, may attribute to the sputtering effect and an insulating effect due to the buildup of the non-conductive coatings. The insulation of the passive film will increase the electric resistance of the circuit and result in a gradual decreasing current flow and finally distinguishing the glow discharge. The time for the glow discharge to extinguish increases as the DC applied voltage increases, as indicated by arrows in Fig. 2 .

\subsection{FTIR}

The IR spectra of HMDSN monomer, as shown in Fig. 3a, are characterized by the asymmetric $\mathrm{Si}-\mathrm{N}-\mathrm{Si}$ stretching at $939 \mathrm{~cm}^{-1}$, the $\mathrm{Si}-\mathrm{N}$ bending at 1186 $\mathrm{cm}^{-1}$, the $\left(\mathrm{Si}-\mathrm{CH}_{3}\right)_{3}$ stretching vibration at $850 \mathrm{~cm}^{-1}$, the $\mathrm{Si}-\mathrm{CH}_{3}$ rocking at $1258 \mathrm{~cm}^{-1}$, and the stretching vibrations of methyl groups around $2960 \mathrm{~cm}^{-1}, 2923$ $\mathrm{cm}^{-1}$ and $2853 \mathrm{~cm}^{-1}[25,29]$. In contrast to the spectra of PHMDSN film shown in Fig. 3b-e, these absorption intensities of the methyl group obviously decrease with increasing the applied DC voltage. At higher power densities, as in the case of the RF power [30], it is likely that a higher degree of methyl abstraction will occur, i.e. recombination with other methyl groups would occur to form volatile hydrocarbons, which are swept away by the pump. Since $\mathrm{Si}-\mathrm{N}$ is liable to dissociate due to the lower bond energy [29], the absorption peaks for a $\mathrm{Si}-\mathrm{N}$ bond, appearing at $939 \mathrm{~cm}^{-1}$ and 1186 $\mathrm{cm}^{-1}$, for the HMDSN monomer almost disappear for all the PHMDSN films.

The $\mathrm{Si}-\mathrm{H}$ stretching band at $2130 \mathrm{~cm}^{-1}$ appears at the PHMDSN and the absorption intensity increases with increasing the applied $\mathrm{DC}$ voltage. The $\mathrm{Si}-\mathrm{H}$ species probably arises from the recombination reactions in the gas phase. The $\mathrm{Si}-\mathrm{H}$ group in the plasma polymer, which is not contained in the monomer, may be formed from the cleavage of the $\mathrm{Si}-\mathrm{CH}_{3}$ group or the $\mathrm{Si}-\mathrm{N}$ group. The higher the applied DC voltage, the more the fragmentation and rearrangement, which leads to more $\mathrm{Si}-\mathrm{H}$.

The HMDSN monomer contains no oxygen. However, the IR spectra of PHMDSN show some peaks associated with the groups containing the oxygen, such as the asymmetric $\mathrm{Si}-\mathrm{O}$ vibration around $1020 \mathrm{~cm}^{-1}$. The oxygen in the deposited film may come from the moisture of the chamber and also possibly from the trace impurity in the monomer and in the argon gas. Due to the high bonding energy between $\mathrm{Si}$ and $\mathrm{O}$, the oxygen will be readily incorporated into the siliconoxide-like film. As the applied DC voltage increases, the $\mathrm{Si}-\mathrm{O}$ peak will broaden and its intensity will increase. That implies the film prepared at higher voltage will have a longer polymer chain and a higher degree of cross-linkage with $\mathrm{Si}$ backbone [31]. It can be concluded that the higher DC voltage will produce a film having a less organic nature.

Fig. 4 shows the IR spectra of PHMDSN film deposited for various times under $1000 \mathrm{~V}$. The relative intensities associated with methyl and $\mathrm{Si}-\mathrm{H}$ groups seem to be the same, while the $\mathrm{Si}-\mathrm{O}$ absorption peak broadens and increases with the increase in deposition time. It implies that the successive bombardment of

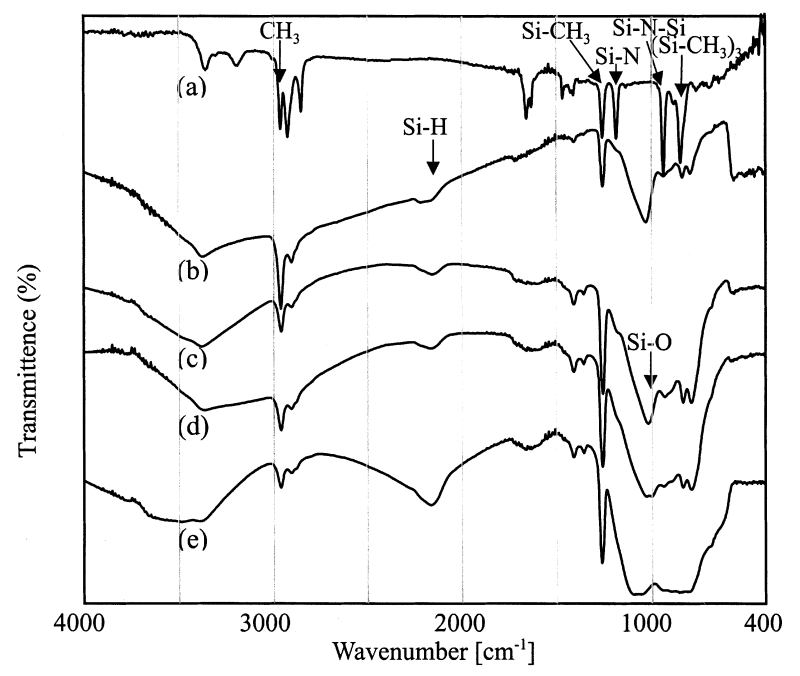

Fig. 3. FTIR spectra of films deposited by DC PHMDSN at 250 mtorr for $308 \mathrm{~s}$ under different DC voltages: (a) HMDSN monomer; (b) $800 \mathrm{~V}$; (c) $1000 \mathrm{~V}$; (d) $1200 \mathrm{~V}$; and (e) $1400 \mathrm{~V}$. 


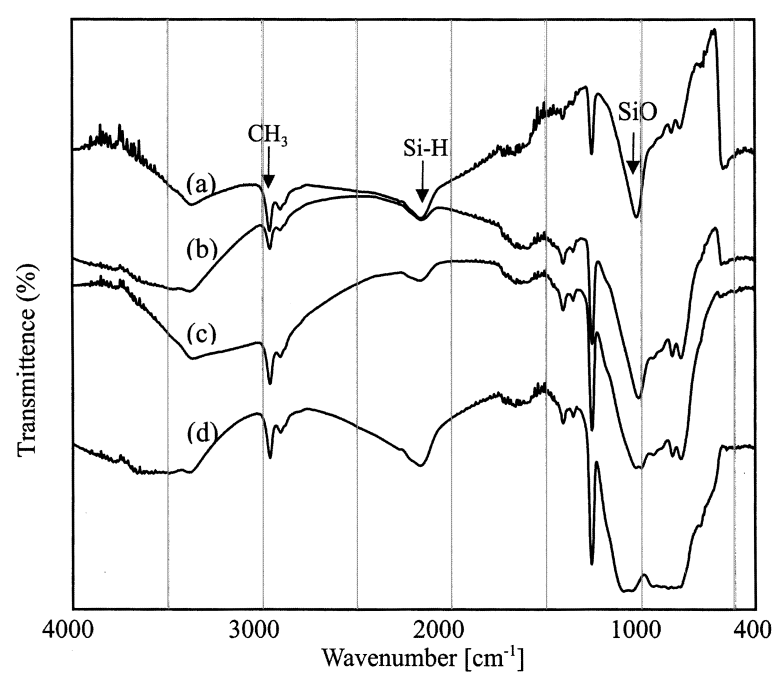

Fig. 4. FTIR spectra of films deposited by DC PHMDSN at 250 mtorr under $1000 \mathrm{~V}$ for various time periods: (a) $100 \mathrm{~s}$; (b) $200 \mathrm{~s}$; (c) $308 \mathrm{~s}$; and (d) $430 \mathrm{~s}$.

deposited film during deposition will not cause further demethylation and dehydrogenation, but will result in further cross-linkage in the deposited films. The ceasing in demethylation and dehydrogenation may result from the protection of the outmost layer of the deposited film.

\subsection{Water contact angle}

The TiNi alloy can be modified substantially into a hydrophobic surface by DC PHMDSN coatings, as illustrated in Table 2. Since the inorganic nature of the plasma polymer exhibits a hydrophilic property [32], the increasing applied DC voltage of the plasma polymerization will slightly reduce the water contact angle. This result is in agreement with the IR spectra shown in Fig. 3.

The water contact angles of films deposited for various time periods under $1200 \mathrm{~V}$ are approximately the same, i.e. $93^{\circ}$. The fact that the surface energy corresponds well with the chemical structure of the surface [32] implies that the chemical structure of the outermost layer of the deposited film is similar, regardless of the duration of applied DC voltage, indicating that the deposition process is a steady-state deposition.

\subsection{Corrosion resistance}

Fig. 5a shows the cathodic and anodic polarization Tafel curves for the virgin TiNi substrate. The curve is almost the same as those reported in the literature [9]. The flat portion of the curve, known as the passive region, indicates that the TiNi readily forms a passive film. The open circuit potential (OCP) and the corro- sion rate are approximately $0.389 \mathrm{~V}$ and $14.6 \mu \mathrm{A} / \mathrm{cm}^{-2}$, respectively. However, the reproductivity of the breakdown (pitting) potential for the as-homogenized TiNi is poor and ranges from $0.712 \mathrm{eV}$ to $1.299 \mathrm{eV}$ and gives widely scattered results, as reported in many studies [14-17].

The effect of the PHMDSN coatings deposited at 250 mTorr under a variety of applied DC voltages on the polarization curve of TiNi alloy is also illustrated in Fig. 5. Fig. 5b, which shows the PHMDSN coating under the $800 \mathrm{~V}$ for $308 \mathrm{~s}$, emphasizes that, although the film has some protection against the corrosion around $\mathrm{OCP}$, the passive film seems to be insufficient to resist corrosion at higher anodic polarization. However, the polarization curve seemingly returns to the PHMDSN-protective behavior as further anodic polarization proceeds. That implies the PHMDSN film promotes the healing of the passive film on TiNi. Nevertheless, the re-passivation ability is almost as poor as the as-homogenized TiNi. For the PHMDSN coatings with the higher DC voltage, as shown in Fig. $5 c-e$, the improvement of corrosion resistance is very remarkable. The fluctuation at the voltage below the breakdown potential is associated with the electrical noise due to the resolution limitation of the potentiostat. The PHMDSN film on TiNi can reduce the current density by at least four orders of magnitude. The failure for the $800 \mathrm{~V}$ case can be attributed to the passive film with a thinner thickness and less cross-linking, i.e. less inorganic in nature, in contrast to the PHMDSN films deposited at higher voltages. At the same time, the outstanding improvement shown in Fig. $5 \mathrm{c}-\mathrm{e}$, when compared with the RF PPTFE film on TiNi [22], may be attributed to the higher resistance and the more homogeneity (pinhole-free) of the deposited film. The hydrophobic and pinhole-free properties will prevent the TiNi from water uptake, leading to lower ionic conduction by many orders of magnitude [33]. The higher thickness of the PHMDSN film, compared to that of the PPTFE film, may also account for the substantial improvement. The high ohmic resistance of the PHMDSN coatings causes the OCP to become very unstable, because the input impedance of the potential measuring device is comparable to the coatings [34]. The pitting potential increases from $1.299 \mathrm{~V}$ (for the maximum case) for the as-homogenized TiNi to approximately $1.460 \mathrm{~V}$ for the TiNi alloy with PHMDSN coatings when being deposited under DC voltage of

Table 2

Water contact angles of PHMDSN films on TiNi alloy deposited at 250 mtorr for $308 \mathrm{~s}$ under different voltages

\begin{tabular}{llllll}
\hline Voltage (V) & 0 & 800 & 1000 & 1200 & 1400 \\
\hline$\theta_{\text {water }}$ & $59^{\circ}$ & $96^{\circ}$ & $96^{\circ}$ & $93^{\circ}$ & $91^{\circ}$ \\
\hline
\end{tabular}



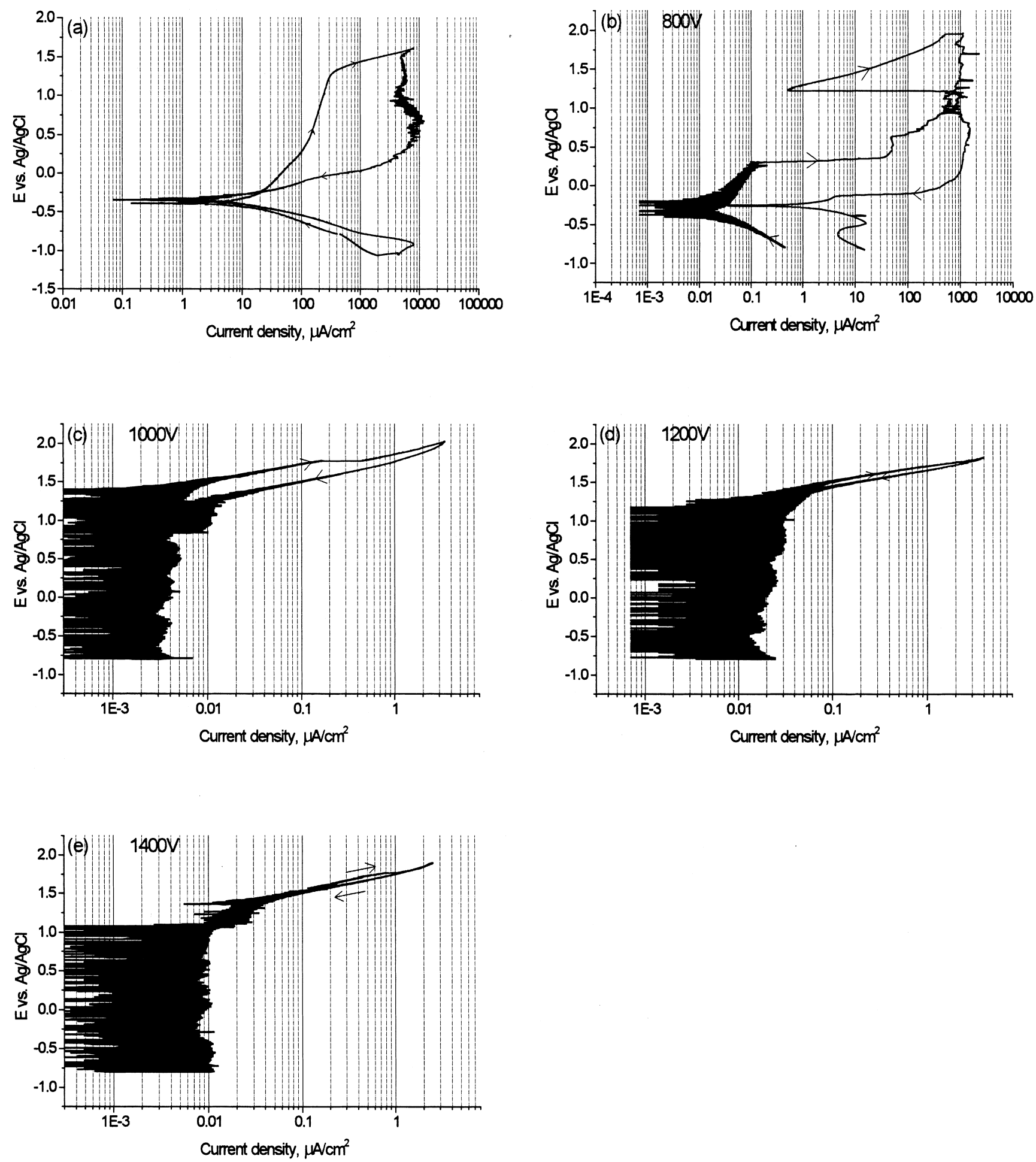

Fig. 5. Tafel plots in Ringer's solution of various specimens with PHMDSN coatings prepared at 250 mtorr for $308 \mathrm{~s}$ under different applied DC voltages: (a) as-homogenized TiNi substrate; (b) $800 \mathrm{~V}$; (c) $1000 \mathrm{~V}$; (d) $1200 \mathrm{~V}$; and (e) $1400 \mathrm{~V}$.

over $1000 \mathrm{~V}$. Moreover, the scattered pitting potential of the as-homogenized TiNi can also be improved by the PHMDSN coatings.

Another remarkable effect of the passive films of the DC PHMDSN coatings is the transition of the re- passivation voltage toward the noble potential. For the as-homogenized $\mathrm{TiNi}$, the low re-passivation potential $(-0.247 \mathrm{~V})$ indicates that the healing of the passive film is difficult and relatively slow. For PHMDSN coatings, the increase in voltage used in DC plasma po- 
lymerization will, seemingly, steadily enhance the repassivation potential. Hence, it can be concluded that the PHMDSN coatings can enhance the pitting potential as well as the re-passivation potential and improve the reproductivity of the pitting resistance. These improvements by DC PHMDSN coatings make the TiNi more reliable in the corrosion resistance, as compared to the RF PPTFE film [22]. The very low current density along the forward scan and the extremely small hysteresis exhibited by the specimen, as shown in Fig. $5 \mathrm{c}-\mathrm{e}$, reflect the high passivity of the PHMDSN-coated $\mathrm{TiNi}$, which in turn indicates that the pitting attack would be impossible under normal physiological conditions.

Although the potentiodynamic polarization is employed in this study for the convenience of the comparison to previous reports [10-22], the AC impedance measurement (electrochemical impedance spectroscopy, EIS) is more suitable to further investigate the characteristics of the passive films with high resistance. The EIS is now under investigation and would be reported separately.

\subsection{Bending test}

For the TiNi wire with PHMDSN coatings (1000 $\mathrm{V} \times 308 \mathrm{~s}$ ), the minimum radius of curvature at which the abrupt decrease of the electric resistance occurs, i.e. the rupture of the deposited film, is $6.3 \mathrm{~mm}$. That is, the PHMDSN can withstand approximately $2 \%$ strain deformation before rupture, using the equation of the bending kinematics [35], $\varepsilon=r / \rho$, where $r$ and $\rho$ are the radius of the TiNi wire and the radius of the curvature of the TiNi wire, respectively. In this study, $r=\phi / 2=$ $0.125 \mathrm{~mm}$ and $\rho=6.3 \mathrm{~mm}$.

\section{Conclusions}

The TiNi corrosion resistance can be substantially improved by the DC plasma-polymerized hexamethyldisilazane (PHMDSN) coatings. The initial PHMDSN deposition rate increases with increasing the DC voltage used in plasma glow discharge. The deposition rate decreases gradually with time until the glow discharge is distinguished. The higher DC voltage used in plasma polymerization will develop a film with a more inorganic nature from the IR spectrum analysis and water contact angle measurements. The PHMDSN coatings for DC voltage $\geq 1000 \mathrm{~V}$ are protection against the corrosion in Ringer's solution and can be deformed up to a $2 \%$ strain. The corrosion current density of the TiNi can be lowered by as many as four orders of magnitude. The pitting potential and re-passivation potential of TiNi alloy can also be enhanced to nobler potential after PHMDSN coatings. Moreover, the widely scattered pitting potential of the as-homogenized TiNi can also be improved by the PHMDSN coatings.

\section{Acknowledgements}

The authors are indebted to Mr Yen-Hon Chen, Institute of Materials Engineering, Tatung University, Taipei, for his assistance in the experimental work. The authors are also pleased to acknowledge the financial support of this research by the National Science Council (NSC), Republic of China, under the Grant NSC882216-E002-026.

\section{References}

[1] C.M. Jackson, H.J. Wagner, R.J. Wasilewski, 55-Nitinol - the Alloy with a Memory: its Physical Metallurgy Properties and Applications, NASA-SP 5110, 1972.

[2] T.G. Frank, W. Xu, A. Cuschieri, SMT-97: Proceedings of the 2nd International Conference on Shape Memory and Superelastic Technology, California, USA, 1997, p. 509.

[3] J.L. Longás, J.A. Puértolas, R. Ríos, M.A. de Gregorio, R. Aguirán, SMT-97: Proceedings of the 2nd International Conference on Shape Memory and Superelastic Technology, California, USA, 1997, p. 567.

[4] L'H. Yahia, G. Droin, C.H. Rivard, N. Hagemeister, M. Assad, M. Masson, Biomater. Living Syst Int. 2 (1994) 79.

[5] D. Reynaerts, J. Peirs, H. Van Brussel, SMT-97: Proceedings of the 2nd International Conference on Shape Memory and Superelastic Technology, California, USA, 1997, p. 555.

[6] S.A. Shabalovskaya, Bio-Med. Mater. Eng. 6 (1996) 267.

[7] F.C. McLean, M.R. Urist, Bone Fundamentals of the Physiology of Skeletal Tissue, 3rd ed., The University of Chicago Press, 1973, p. 64

[8] K. Takaurra, K. Hayashi, N. Ishinishi, T. Yamada, Y. Sugioka, J. Biomed. Mater. Res. 28 (1994) 583.

[9] H. Zitter, H. Plenk, Jr., J. Biomed. Res. 21 (1987) 881.

[10] P. Filip, V. Tomasek, K. Mazanec, Metallic Mater. 32 (2) (1994) 63.

[11] D.J. Wever, A.G. Veldhuizen, M.M. Sanders, J.M. Schakenraad, J.R. van Horn, Biomaterials 18 (1997) 1115.

[12] K.M. Speck, A.C. Fraker, J. Dent. Res. 59 (10) (1980) 1590.

[13] G. Rondelli, Biomaterials 17 (1996) 2003.

[14] Y. Nakayama, T. Yamamuro, Y. Kotoura, M. Oka, Biomaterials 10 (1989) 420.

[15] F. Villermaux, M. Tabrizan, L'H. Yahia, M. Meunier, D.L. Piron, Appl. Surf. Sci. 109/110 (1997) 62.

[16] N.K. Sarkar, W. Redmond, B. Schwaninger, A.J. Goldberg, J. Oral Rehabil. 10 (1983) 121.

[17] H. Kimura, T. Sohmura, Dent. Mater. Apparatus 6 (1) (1987) 73.

[18] C. Sella, J.C. Martin, J. Lecocur et al., Mater. Sci. Eng. A139 (1991) 49.

[19] S.K. Wu, C.L. Chu, H.C. Lin, Surf. Coat. Tech. 92 (1997) 206.

[20] D.M. Grant, S.M. Green, J.V. Wood, Acta Metall. Mater. 43 (3) (1995) 1045

[21] C. Trépanier, M. Tabrizian, L'H. Yahia, L. Bilodeau, D.L. Piron, Mat. Res. Soc. Symp. Proc., Pittsburgh, PA, USA Materials Research Society, 459 (1997) 363.

[22] F. Villermaux, M. Tabrizian, L. Yahia, G. Czeremuszkin, D.L. Piron, Bio-Med. Mater. Eng. 6 (1996) 241. 
[23] M.R. Yang, K.S. Chen, J.L. He, Mater. Chem. Phys. 48 (1997) 71.

[24] D.J. Li, F.Z. Cui, H.Q. Gu, J. Zhao, Appl. Surf. Sci. 126 (1998) 1.

[25] S. Eufinger, W.J. van Ooij, T.H. Ridgway, J. Appl. Polym. Sci. 61 (1996) 1503.

[26] W.J. van Ooij, S. Eufinger, S. Guo, Plasma Chem. Processing 17 (2) (1997) 123.

[27] A.M. Sarmadi, T.H. Ying, F. Denes, Eur. Polym. J. 31 (9) (1995) 847.

[28] R. d'Agostino, Plasma Deposition, Treatment, and Etching of Polymers, Academic Press, Inc, Boston, 1990.

[29] G. Grundmeier, M. Stratmann, Ber. Bunsenges. Phys. Chem. 99 (11) (1995) 1387.
[30] M.P. Bonnar, B.M. Burnside, A. Little, R.L. Reuben, J.I.B. Wilson, Adv. Mater. 9 (10) (1997) 201.

[31] E. Radeva, D. Tsankov, K. Bobev, L. Spassov, J. Appl. Polym. Sci. 50 (1993) 165.

[32] L. Zuri, M.S. Silverstein, M. Narkis, J. Appl. Polym. Sci. 62 (1996) 2147.

[33] R.E. Barker, Jr., Pure Appl. Chem. 46 (1976) 157.

[34] S.R. Taylor, IEEE Trans. Electrical Insulation 24 (5) (1989) 787.

[35] D.L. Logan, Mechanics of Materials, Harper Collins Pub. Inc, New York, 1991, p. 243. 